\title{
Power of stable isotope techniques to detect size-based feeding in marine fishes
}

\author{
D. E. Galván ${ }^{1, *}$, C. J. Sweeting ${ }^{2}$, W. D. K. Reid ${ }^{2}$ \\ ${ }^{1}$ Centro Nacional Patagónico, Boulevard Brown s/n, (U9120ACV) Puerto Madryn, Chubut, Argentina \\ ${ }^{2}$ School of Marine Science and Technology, Newcastle University, Newcastle Upon Tyne NE1 7RU, UK
}

\begin{abstract}
Stable isotope techniques are now the most frequently applied method to investigate size-based variation in fish trophic position (TP), and data suggest changes in TP with body size are common. However, of 131 collated investigations of the relationship between body size and $\delta^{15} \mathrm{~N}$ for inshore coastal fishes, approximately $60 \%$ were non-significant. The present study tests whether non-significant trends reflect a true feeding pattern, a lack of statistical power, or a function of both. Results suggest none of these studies for which correlation coefficients were available, achieved enough statistical power to rigorously assess observed slopes. The sample size required to detect statistically significant trends of different magnitude, given assumptions of dispersion and observed data on body size range sampled, was then assessed. Even under lenient assumptions of below average dispersion and uniform sampling effort across the sampled body size range, $<10 \%$ of the statistical tests classifying trends as non-significant had the power to detect a slope corresponding to a 0.25 change in TP over $80 \%$ of maximum length (proportional length range: $L_{\max }$ ) throughout life. Therefore non-significant trends in $\delta^{15} \mathrm{~N}$ are predominantly the result of poor power, and no conclusion can be drawn as to associated fish trophodynamics. Analysis here suggests that size-based feeding studies should aim to sample over $40 \% L_{\max }$ range of the population, as the sample size required to maintain sufficient statistical power diminishes almost exponentially with increasing body size range. Researchers should strive to minimise other sources of variation as linear increases in dispersion lead to virtually linear increases in sample size necessary to maintain power. Finally, a key component of hypothesis testing for size-based feeding should be not just whether a trend is significant, but whether sampling is adequate to detect a minimum ecologically relevant threshold slope. This will separate tests that lack power from those where size-independent feeding is a true feeding mode.
\end{abstract}

KEY WORDS: Diet $\cdot$ Regression $\cdot$ Ontogenetic $\cdot$ Sulphur $\cdot$ Nitrogen $\cdot$ Trophodynamic $\cdot$ Production Resale or republication not permitted without written consent of the publisher

\section{INTRODUCTION}

Body size is a fundamental determinant of fish trophodynamics (Peters 1983). Food intake, foraging ability, and potential range of prey all generally increase with size (Cohen et al. 1993, Reid et al. 2007) resulting in predators being typically larger than their prey (Jennings et al. 2008a). Predators generally increase in trophic position (TP) throughout their life as a result of ontogeny first and then through subsequent growth. The need to understand these 2 processes of size-based changes in feeding are particularly important for understanding the driving forces behind community structure and fisheries management.
While size-based feeding has been documented in a number of studies based on gut content (Stergiou \& Karpouzi 2002), the time- and labour-intensive nature of this technique often limits application to commercially or ecologically important species. Stable isotope analyses (SIA) provide an alternative approach to estimation of TP as well as the potential to describe the source of primary production sustaining different species or size classes. The use of SIA in size-based feeding studies has reduced the sample size compared to gut content based studies because stable isotopes can derive TP data for individuals in relation to suitable baseline values. TP has repeatedly been shown to be positively correlated to the stable isotope ratio of ${ }^{15} \mathrm{~N}$ to ${ }^{14} \mathrm{~N}$, expressed as $\delta^{15} \mathrm{~N}$ (e.g. Jennings et al. 2002). 
Improvements in analytical instrumentation and reductions in per sample cost have ensured widespread adoption of the stable isotope technique (Jennings et al. 2008a).

Numerous studies have applied isotope techniques to the investigation of size-based feeding. The most comprehensive datasets to date (Davenport \& Bax 2002, Jennings et al. 2002) suggest that size-based feeding is common. Both derive results from planktonic-driven continental shelf ecosystems where sizebased feeding is expected to be strong. Despite this, substantial numbers of species $(\sim 40 \%)$ exhibit nonsignificant trends (Jennings et al. 2002). In more complex systems with a greater array of production sources and weaker size structuring (Layman et al. 2005), the potential for non-significant trends is greater.

It is, however, unclear whether non-significant data in more complex inshore systems reflect a true feeding pattern or a lack of statistical power. Defining the relative proportions of each would be informative in interpreting size-based feeding behaviour and stimulating correct experimental design. The majority of studies that test size-based feeding apply linear regression techniques. This choice, as opposed to an ANOVA with multiple size classes, is the right and powerful choice (Cottingham et al. 2005) for size-based trends.

The earliest isotope study to examine size-based feeding using SIA was Rau (1981) on Dover sole Microstomus pacificus. With a sample size of $\leq 6$, the study would fail to detect a significant body size effect despite an $\mathrm{R}^{2}$ in excess of 0.70 . Menard et al. (2007) also found $\delta^{15} \mathrm{~N}$ independent of body size in yellowfin tuna Thunnus albacares, although in this case a sample size of 244 individuals lends confidence to their conclusions. These 2 studies are illustrative of the issue of separating studies genuinely exhibiting feeding patterns from studies with limited power.

The statistical power (1- $\beta$ ) of a linear regression to detect a significant dependence of the response variable on a predictor is related to both sample size (n) and to the strength of the correlation (r) (Dupont \& Plummer 1998). $r$ in turn is a function of the magnitude of the slope $(b)$, the range of predictor $(\Delta x)$, the distribution of data within $\Delta x$, and the degree of dispersion $\left(\sigma_{\varepsilon}\right)$ in the response. Dispersion can be quantified as $\sigma$, the standard deviation (SD) of the residuals $\varepsilon$. Expressed in terms of size-based diet shifts in fish, statistical power is a function of the sampled body size range $\left(\Delta x=\Delta L_{\max }\right)$, the distributions of samples within that size range, the magnitude of the trophic change $(\Delta \mathrm{TP})$ with body size $(b=$ slope of the $\delta^{15} \mathrm{~N}-L_{\max }$ regression) and the variability in $\delta^{15} \mathrm{~N}$ for a given body size $\left(\sigma_{\varepsilon}=\mathrm{SD}\right.$ of $\left.\delta^{15} \mathrm{~N}_{\text {observed }}-\delta^{15} \mathrm{~N}_{\text {predicted }}\right)$.

Given $\mathrm{R}^{2}$ and $\mathrm{n}$, the power of a regression is easily determined. However, in individuals with no size-based feeding, hundreds of samples may be required to achieve acceptable levels of power $(1-\beta=0.80)$, and almost all data eventually exhibit significance given enough sampling effort regardless of how meaningful the effect. A more pertinent question is whether the statistical analyses had the power to detect some ecologically meaningful threshold effect. In this way, power analysis may be used to separate studies revealing true feeding patterns from under-sampled studies if ecologically meaningful threshold levels of $b$ can be defined. Given observed levels of $n, \sigma_{\varepsilon}$ and $\Delta L_{\text {max }}$ it is possible to test whether any given study had the power to detect the desired $b$. Those that do have sufficiant power but detect no significant effect, suggest $\delta^{15} \mathrm{~N}$ is independent of body size and represent a true feeding behaviour, while those that do not achieve the desired power lack the ability to differentiate trends.

The threshold effect approach described above is used here to assess how frequently non-significant trends between $\delta^{15} \mathrm{~N}$ and body size in marine fishes are attributed to true feeding behaviour or simply result from a lack of statistical power, particularly size-based trends in fish sampled at complex inshore habitats. The definition of an ecologically significant threshold effect may vary with perspective, the isotope used, and study aims. Similarly, power will vary with the level of $\sigma_{\varepsilon}$ and with other factors influencing $r$. Specifically, this study investigates (1) the proportion of non-significant tests of size-based feeding in a data set of marine inshore coastal fishes; (2) how many of these tests achieved sufficiant statistical power for detecting observed slopes based on associated $\mathrm{r}$ or $\mathrm{R}^{2}$ data; and (3) given lenient assumptions of dispersion, how many tests would have been powerful enough to detect ecologically meaningful diet shifts of between 0.25 and 1.0 TPs in magnitude. In investigating the impacts of assumptions of dispersion and threshold effect on conclusions, the present study also allows the provision of guidance for testing size-based feeding behaviour.

\section{MATERIALS AND METHODS}

Ontogenetic or size-based feeding data for inshore coastal fishes described by $\delta^{15} \mathrm{~N}$ were collated from the literature using Institute for Scientific Information (ISI) literature database key word searches (combinations of "isotop*", "trophic", "size", "ontogenetic", "fish*", "diet", "feeding", "reef", "lagoon", "estuarine", and "marine") and followed up by a search through forward and backward citations. The literature survey covered January 1977 to July 2009 (see Supplement 1 at www.int-res.com/articles/suppl/m407p271_app1.pdf). Further criteria for inclusion were data obtained from nominally complex communities including brackish, vegetated, and biogenic habitats. 
Information on $\mathrm{n}, b, \mathrm{R}^{2}$, body size range, and slope significance was then extracted from collated literature. The sampled body size range and slope of the isotope-size regression were converted from minimum and maximum unit length ( $\mathrm{mm}$ or $\mathrm{cm}$ ) to proportional length range $\left(\Delta L_{\max }\right)$ to standardise among species. $L_{\max }$ were obtained from FishBase (Froese \& Pauly 2009). Regressions were then assessed for $1-\beta$ using a 1-tailed test, Eq. (1) (Pértega Díaz \& Pita Fernández 2002):

$$
Z_{1-\beta}=\sqrt{n-3} \frac{1}{2} \ln \left(\frac{1+r}{1-r}\right)-Z_{1-\alpha}
$$

where $\mathrm{n}$ represents sample size and $\alpha$ is the probability of falsely accepting the alternative hypothesis when in fact the null hypothesis is true and was set at 0.05 . $1-\beta$ was set at 0.80 and equals the probability of falsely accepting the null hypothesis when in fact the alternative hypothesis is true.

To categorise data retrospectively as either (1) adequate to identify true feeding behaviour or (2) insufficient in sample size, the sample size needed to achieve $1-\beta$ of 0.80 was determined based on a threshold $b$ and estimated $\sigma_{\varepsilon}$ in combinations with the observed $\Delta L_{\text {max }}$ assuming a uniform distribution of data across the sampled body size range $\left(\Delta L_{\max }\right)$. Where the observed $\mathrm{n}\left(\mathrm{n}_{\text {obs }}\right)$ was greater than $\mathrm{n}$ required to achieve sufficient power $\left(\mathrm{n}_{1-\beta}\right)$, data were categorised as adequate (true feeding behaviour). When $\mathrm{n}_{\text {obs }}$ was less than $\mathrm{n}_{1-\beta}$, data were categorised as under-sampled (lacking statistical power).

$\mathrm{n}_{1-\beta}$ was derived by fitting linear models to simulated datasets of 100000 samples with an independent variable $X$ created as a random sample with uniform distribution on $\Delta L_{\max }$ intervals and a dependent variable $Y$ constructed by Eq. (2):

$$
Y=b X+\varepsilon
$$

where $Y$ represents the $\delta^{15} \mathrm{~N}$ value, $X$ the sampled body size range as $L_{\max }$ and $\varepsilon$ the error term, which was constructed as 100000 samples normally distributed with mean $=0$ and $\mathrm{SD}=0 \sigma$. All the calculations were done using the statistical software R V.2.5.0 (R Development Core Team 2007) (source code in Supplement 2 at www.int-res.com/articles/suppl/m407 p271_app2.txt).

This paper determined the minimum threshold effect as a 0.25 change in TP throughout life. This equates to $b=0.01$ assuming a nitrogen diet-tissue fractionation of $3.2 \%$ (Sweeting et al. 2007a). This was based on ultimate interests in impacts of exploitation on marine populations.

As this study retrospectively estimates statistical power of studies, observed $\sigma_{\varepsilon}$ was not available. $\sigma_{\varepsilon}$ was set at \pm 0.3 , derived from Sweeting et al. (2005) for fish on a constant diet. Although $\Delta L_{\max }$ was collected, the distribution of samples within $\Delta L_{\text {max }}$ was unavailable. For simplicity, sampling of body size was assumed uniform throughout the range and this combined with a $\sigma_{\varepsilon}$ from fish on constant diet represents the lenient scenario most readily assessing studies to have adequate power. Stricter scenarios were assessed by alter$\operatorname{ing} \sigma_{\varepsilon}$.

As $\sigma_{\varepsilon}, \Delta L_{\text {max }}$ and the threshold $b$ may vary among studies, and both $b$ and $\mathrm{R}^{2}$ are derived variables that may be altered by context, the effect of variation in the former parameters on $\mathrm{n}_{1-\beta}$ was assessed. $\mathrm{n}_{1-\beta}$ requirements were also assessed for TP changes of $0.33,0.5$, and 1.0 over $80 \% L_{\max }(b=0.0166,0.02$, and 0.04 , respectively). Variation on $\sigma_{\varepsilon}$ was assessed in 0.02 increments from \pm 0.1 to \pm 1.5 , representing the best analytical precision and high variability of young wild fishes with high turnover feeding on an unknown diet (Sweeting et al. 2005), respectively.

\section{RESULTS}

The literature review obtained 131 tests of trends or differences in $\delta^{15} \mathrm{~N}$ with body size from 31 studies (Supplement 1) and 86 species. Linear regression was the dominant form of statistical analysis, constituting $64.89 \%$. Pearson's correlation constituted $6.87 \%$. $14.50 \%$ of tests utilised Spearman's rank, while all remaining analyses were of the ANOVA family (ANOVA, mixed ANOVA, $t$-test, and so on) and totalled only $13.74 \%$.

There was no evidence that researchers have increased sample size through time when assessing feeding behaviour by means of linear regression. Of all tests, $60.31 \%$ were non-significant, with this proportion almost uniform among statistical techniques. Of the linear regressions and Pearson's correlations, $60.63 \%$ exhibited no significant trend between $\delta^{15} \mathrm{~N}$ and size; $36.17 \%$ exhibited significant positive trends; and $3.19 \%$ significant negative trends. Only a quarter of tests reporting non-significant results gave correlation coefficients. Utilising these, none of the tests achieved a satisfactory power of $80 \%$ to adequately test slope significance. Power instead ranged from 0.06 to $58.39 \%$.

However, it is more informative to examine whether tests had the statistical power to detect effects of ecological significance. Using the sampled $\Delta L_{\max }$ and $\mathrm{n}_{\mathrm{obs}}$ for each regression and assumptions of dispersion $\left(\sigma_{\varepsilon}=0.3\right)$, proportions of $6,9,27$, and $63 \%$ of the nonsignificant regressions achieved a statistical power of 0.8 with threshold effects of $\Delta \mathrm{TP}=0.25,0.33,0.50$, and 1.0, respectively (Fig. 1). These represent the maximum number of studies with reliable non-significant 


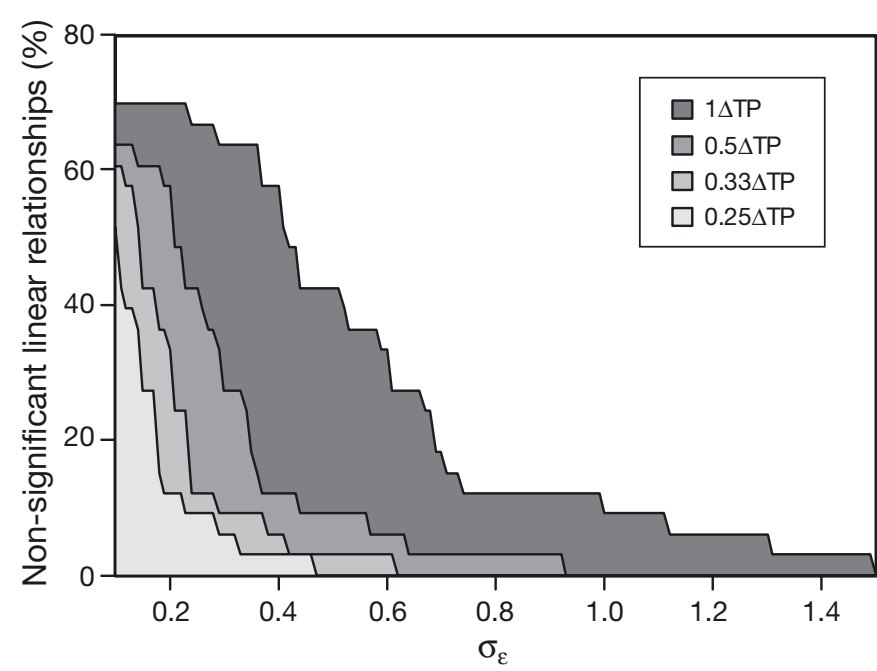

Fig. 1. Percentage of non-significant linear relationships with sample size $(\mathrm{n})$ bigger than the minimum $\mathrm{n}$ required to achieve power $(1-\beta)$ of $0.8\left(n_{1-\beta}\right)$ given observed proportional length range $\left(\Delta L_{\max }\right)$ and assuming uniform sampling across $\Delta L_{\max }$, degree of dispersion $\sigma_{\varepsilon}=0.3$, and different threshold lifetime changes in trophic position $(\Delta \mathrm{TP})$

trends, i.e. studies that can be considered having adequate power, because higher levels of $\sigma_{\varepsilon}$ and infringements of the assumption of uniform sampling effort across $\Delta L_{\max }$ will only reduce power and thus the proportion of the dataset that was allocated to a true feeding behaviour. For example, for $\sigma_{\varepsilon}>0.46$ or 0.61 , no conclusion could be drawn regarding size-based feeding from any study using $\Delta \mathrm{TP}=0.25$ and 0.33 as threshold effects, respectively (Fig. 1). This suggests that in the majority of cases where non-significant trends were identified, sampling strategies were insufficiant for detecting shifts in feeding behaviour of less than $1 \mathrm{TP}$, which inadequate for many ecological hypotheses.

The formulation of the above post hoc power testing equally allows provision of guidance on better sampling strategy. The statistical power to detect trends dramatically improved with increasing threshold effect and sampled size range (Fig. 2A,B) and with decreasing dispersion (Fig. 2C,D). For any given body size range, linear increases in slope $(\Delta \mathrm{TP})$ led to approximately exponential decreases in the sample size required to obtain sufficiant power (Fig. 2B). Thus $\mathrm{n}_{1-\beta}$ was very sensitive to $\Delta L_{\max }$ throughout but particularly when $\Delta L_{\max }$ was low. Sampling intensity required to detect the defined ecologically important threshold effect began to equalise between 40 and $60 \% \Delta L_{\max }$ and asymptotically converged to a sample size of $\sim 6$ with increasing threshold $(\Delta \mathrm{TP})$. For example, when assessing $\Delta \mathrm{TP}>0.5$, sample size changed little $>30 \%$ $\Delta L_{\max }$. Similarly, increases in $\mathrm{n}_{1-\beta}$ were particularly pronounced when trying to detect effects smaller than
$0.4 \mathrm{TP}$, although this was mediated by increasing $\Delta L_{\max }$ (Fig. 2B). In comparison with other parameters, $\mathrm{n}_{1-\beta}$ increased almost linearly with increasing $\sigma_{\varepsilon}$ given the range of dispersion assessed (Fig. 2C,D). However, the impact of increasing dispersion on $\mathrm{n}_{1-\beta}$ was reduced when both the magnitude of the slope and the sampled size range increased.

\section{DISCUSSION}

The analyses presented here suggest that significant bias exists in current assessment of size-based feeding in marine fishes from inshore coastal habitats. This review indicates the dominant observation was for size-independent feeding. This conclusion is, however, flawed as few tests were capable of detecting even large shifts in feeding behaviour with only 2 papers recognising that sample size was too small and $\Delta L_{\max }$ too narrow.

Sample size, per statistical test of the SIA size-based feeding studies evaluated in the present study, did not increase over time despite reductions in per sample analysis costs. It appears instead that authors have either sampled more species, or the same species across a greater number or spatial/temporal points. This suggests analytical advances have not led to more robust sampling, only to a greater quantity of under-sampled data.

Analysis also highlights that the currently applied simple classification of feeding into significant and non-significant size-based feeding is inadequate. These conclusions are unlikely to be a function of assumptions used within the present meta-analysis, as analyses were lenient in favour of allocation to sizeindependent feeding. Dispersion was set at $0.3 \%$, about $0.1 \%$ lower than the mean SD found in trophic fractionation from reviewed controlled feeding experiments on fish (Sweeting et al. 2007a,b). These analyses also assumed a uniform sampling distribution across $\Delta L_{\max }$. However, unless sample collection is specifically aimed to maintain uniform sampling, large and very small size classes will be under-represented, a result of catchability. This reduced the effective $\Delta L_{\max }$ and thus statistical power.

Given the inadequacies of current investigations allocating fishes to either significant or non-significant trends, it is recommended that either hypothesis testing be taken against some ecologically meaningful threshold or trend slopes are used regardless of significance. The former may be used to separate size independent feeding behaviour from inadequate tests. The latter was used by Jennings et al. (2002) to investigate fishing impacts on North Sea food webs. Results of the present study support this technique assuming 
sample size is adequate for the accurate determination of slope.

The main application of power analysis in experimental design is to understand how many samples are needed to accept the outcome of an insignificant statistical result with a particular level of confidence. This study highlights that sample size, $\Delta L_{\max }$ threshold effect size $(\Delta \mathrm{TP})$ and $\sigma_{\varepsilon}$ are all important determinants of whether a study has the statistical power to detect size-based feeding of marine fish. It illustrates that power diminishes rapidly when sampling is conducted over less than $40 \% \Delta L_{\max }$ and is approximately linearly related to dispersion. The study highlights that simply collecting more samples may not be the most efficient technique to improve power of ecologically motivated questions relating to size driven trophodynamics or feeding patterns of marine fish.

The aforementioned information has considerable potential for refinement of testing true ontogenetic and growth-based feeding patterns. Ontogenetic trends in foraging behaviour and diet switching can be pronounced when individuals develop from larval stages to juveniles (Wells et al. 2008). These are often accompanied by a switch in habitat utilisation (Nagelkerken \& van der Velde 2004). The combination of a diet switch and fast turnover can result in very abrupt changes in stable isotope values over a very narrow size range (Graham et al. 2007, Wells et al. 2008). Within this scenario the potential size range is constrained to be small even if the effect is often large.
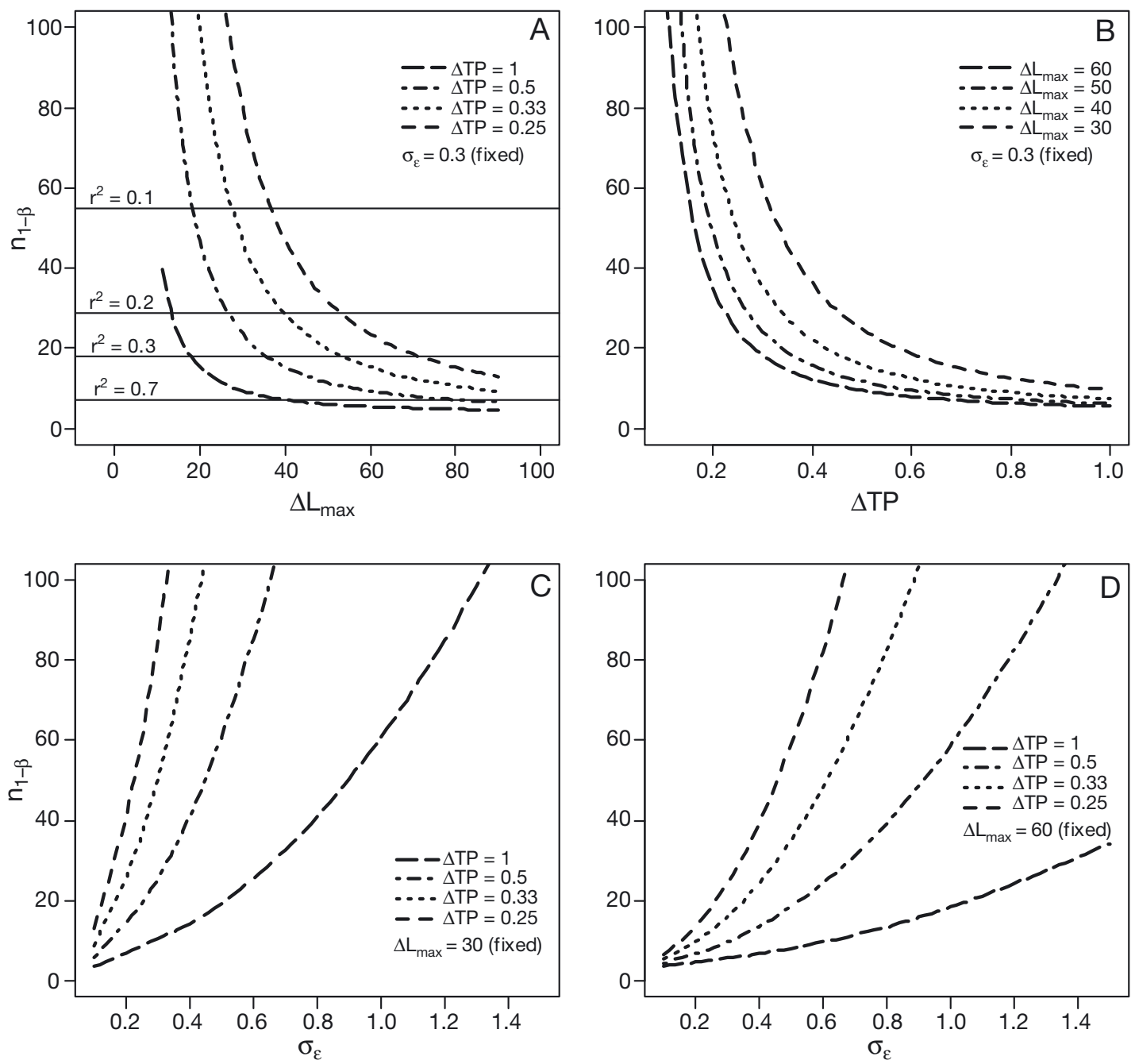

Fig. 2. (A) Sample size required to achieve statistical power of $0.8\left(\mathrm{n}_{1-\beta}\right)$ when sampling was conducted over different body size ranges (proportional length range: $\Delta L_{\text {max }}$ ). Lines represent the power curve assuming a fixed degree of dispersion $\left(\sigma_{\varepsilon}=0.3\right)$ and different threshold effects (change in trophic position: $\Delta \mathrm{TP}$ ). (B) Sample size required to achieve power of 0.8 given a range of threshold effects. Lines represent the power curve assuming $\sigma_{\varepsilon}=0.3$ and different ranges of $L_{\max }\left(\Delta L_{\max }\right)$. (C, D) Sample size required to achieve power of 0.8 when sampling was conducted over different dispersions. Lines represent the power curve for different threshold effects when $\Delta L_{\max }$ was (C) $30 \%$ and (D) $60 \%$ 
Sufficient statistical power is therefore usually achieved by greater sampling effort.

Power increased dramatically with an increase in $\Delta L_{\max }$ up to between 40 and $60 \%$-the higher ranges being necessary to detect smaller threshold effects. Based on data reviewed in the present study, the median $\Delta L_{\text {max }}$ used to date was $30 \%$ and is below the $40 \%$ $\Delta L_{\text {max }}$ where power begins to asymptote, suggesting undersampling of $\Delta L_{\max }$ is common. It also highlights that where adults and post-metamorphic juveniles are found in different locations (Cocheret de la Moriniére et al. 2003), it may be difficult to obtain a large enough size range. Instead, the robustness of hypothesis testing is related to either extensive sampling or the ability to ameliorate the confounding effects of different isotopic baselines among sites and the isotopic disequilibrium period. The latter is induced by lagged isotopic turnover that occurs when individuals move to a location with a different isotopic baseline.

The ability to detect ecologically meaningful trends will improve if a true reflection of dispersion throughout $\Delta L_{\text {max }}$ can be obtained. Variability in $\delta^{13} \mathrm{C}$ and $\delta^{15} \mathrm{~N}$ has been proposed as indicators of trophic niche width (Bearhop et al. 2004, Layman et al. 2007). High variance in $\delta^{15} \mathrm{~N}$ among individuals could be expected for generalist feeders, while low variance may be observed in specialist or generalist feeders feeding on a uniform food supply (Bearhop et al. 2004). When dispersion is high and reflective of real feeding patterns (Layman et al. 2007), then it is even more important to increase sample size to assess how dispersion changes with size. Particular care is required at the extreme ends of $L_{\max }$ where individuals may appear as outliers. Understanding the influence of these points on the regression coefficients is an important part of the data analysis, and there are many good text books that cover this topic (e.g. Zuur et al. 2007). Without an understanding of true dispersion as a result of feeding patterns and good data exploration practices, it may further impact the ability to detect size-related trends between body size and TP.

The ability to detect ecologically meaningful trends will improve if dispersion resulting from experimental, methodological and analytical error can be reduced. Analytical improvements are gained when analysis is restricted to a single machine reducing inter-machine biases (Mill et al. 2008) or by running duplicates. Isotopic baselines are variable in space (Jennings \& Warr 2003, Barnes et al. 2009) and time (Jennings et al. 2008b). Modifications in experimental design performed to reduce dispersion may be achieved by either constraining sampling in space and time or by obtaining accurate baseline data integrated at appropriate scales by isotopic turnover sampling frequency. Similarly, tissues of fish on a constant diet differ in their variability (Sweeting et al.
2005). Utilisation of low variability tissues, e.g. muscle, is recommended. Statistical improvements may be gained by incorporation of other explanatory variables, e.g. gender or morph. Methodological improvements may include lipid extraction or acidification to reduce variation induced by variable lipid contents (Sweeting et al. 2006, Post et al. 2007) or carbonate (Bunn et al. 1995). Accounting for lipids or carbonate effects should be considered even if their influence is not systematic. However, care should be taken with these techniques, as additional processing may also increase variation (Bunn et al. 1995) and cause shifts in $\delta^{15} \mathrm{~N}$ (Murry et al. 2006).

Machine analytical precision and naturally occurring variation in fish fed on a single diet are similar for all 3 most commonly used stable isotopes in ecology (carbon; $\delta^{13} \mathrm{C}$, nitrogen; $\delta^{15} \mathrm{~N}$, and sulphur; $\delta^{34} \mathrm{~S}$ ). Precision of analysis is commonly accepted as $\pm 1 \mathrm{SD}$ and equates to $0.2 \%$ for both carbon and nitrogen isotopes. For sulphur isotope analysis, precision is lower at $\sim 0.4 \%$. However, observations of variation in tissue $\delta^{34} \mathrm{~S}$ from fishes equilibrated with experimental diets (Hesslein et al. 1993, Barnes \& Jennings 2007) are within mean ranges observed of carbon $( \pm 0.42 \%)$ and nitrogen $( \pm 0.38 \%$ ) for trophic fractionation estimates reviewed by Sweeting et al $(2007 a, b)$. Experimental power also varied with effect size; in this case the threshold slope defined is important. Interpretation of an ecologically meaningful slope will vary with user and application. For example, a $0.25 \mathrm{TP}$ increase has a greater relative impact on food chain length in shorter food chains (e.g.

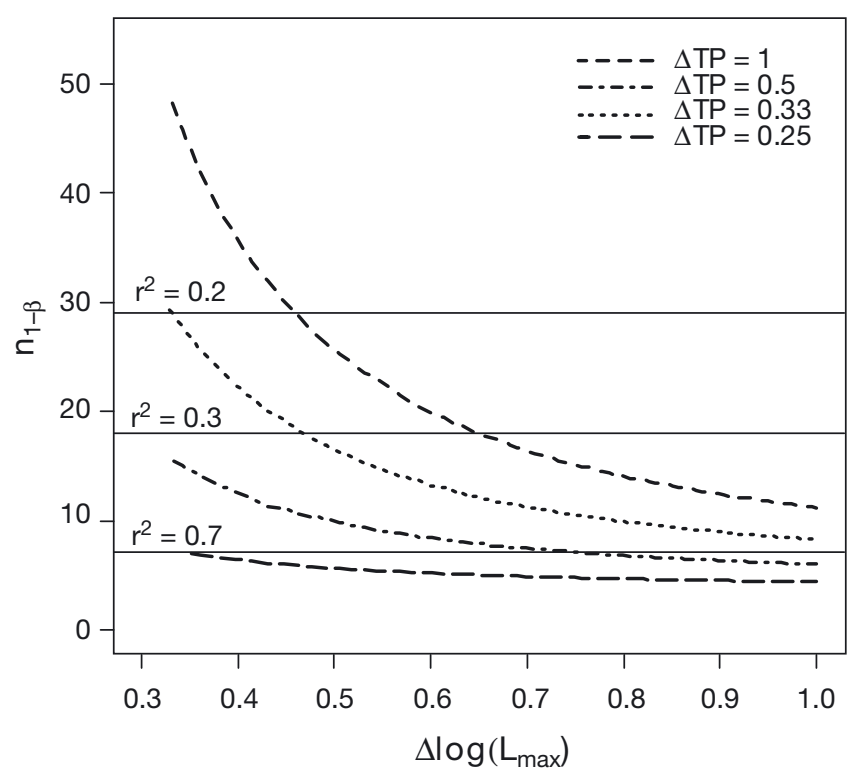

Fig. 3. Sample size required to achieve a statistical power of $0.8\left(\mathrm{n}_{1-\beta}\right)$ when sampling was conducted over different size ranges $\left(\Delta \log L_{\max }\right)$. Fish lengths varied from $10 \%<L_{\max }<21 \%$ to $10 \%<L_{\max }<100 \%$. Lines represent the power curve assuming $\sigma_{\varepsilon}=0.3$ and different threshold effects $(\Delta \mathrm{TP})$ 
3 TP) of upwelling systems compared to open ocean systems with 5 TP (Ryther 1969). It will also vary among isotopes. Isotopic shifts induced by trophic step fractionation of carbon or sulphur are small, but primary production sources may differ dramatically. Therefore, size-based shifts for $\delta^{13} \mathrm{C}$ and $\delta^{34} \mathrm{~S}$ will be small when driven by trophic fractionation alone, but may be very large where changes in source production occur.

Log-linear relationships between fish size and TP are a common pattern in nature (Jennings et al. 2002). In this case, the relationship between the required minimum sample size and the $\Delta L_{\max }$ sampled is different. For example, on a $\log _{10}$ scale the isotopic change between 20 and $50 \%$ of $L_{\max }\left(\Delta L_{\max }=30 \%\right)$ is the same as that between 40 and $100 \%\left(\Delta L_{\max }=60 \%\right)$ on a linear scale. The latter example shows the importance of an intensive sampling regime over the younger life stages to accurately define the relationship within log-linear trends (Fig. 3).

Another important point to note is that under loglinear relationships the minimum sample size required to achieve a statistical power of 0.8 is smaller than under linear relationships if sampling younger life stages and greater if sampling older life stages (Fig. 3). For example, assuming $\Delta \mathrm{TP}=0.25$ and $\sigma_{\varepsilon}=0.3$, the $\mathrm{n}_{1-\beta}$ required to achieve power of 0.8 is 32 if $\Delta L_{\max }=50 \%$ under linear conditions, while it is 22 for smaller fish (20 to $70 \% L_{\max }, \Delta \log L_{\max }=0.544$ ) and 46 for larger fish (40 to $90 \% L_{\max }, \Delta \log L_{\max }=0.352$ ) under log-linear conditions.

Statistical power curves in Fig. 2 were based on assessing the power of linear body size-isotope relationships, the most frequent trend type in the studies reviewed. However, should one desire to assess the statistical power under log-linear conditions, it is possible to estimate the respective minimum sample size $n_{1-\beta}$ under log-linear regressions from this figure using Eq. (3):

$$
b_{1} \Delta L_{\max }=b_{2} \Delta \log L_{\max }
$$

where $b_{1}$ represents the threshold effect of the linear relationship, $b_{2}$ the threshold effect of the log-linear relationship, $\Delta \log L_{\max }$ the difference between the $\log$ values of the maximum and the minimum fish length sampled and $\Delta L_{\max }$ the value that gives an equivalent power under the same sample size. This then assumes equal sampling effort with size on a log scale rather than a linear scale.

The above discussion provides some guidance on experimental design. Methodologies developed here were principally designed for the post hoc examination of existing tests where dispersion and sampling distribution within $\Delta L_{\max }$ are unknown. If authors follow uniform sampling, the R code in Supplement 2 may be used with observed levels of dispersion to assess the statistical power for detecting threshold effects. However, deviations from the assumption of uniform sampling make determinations increasingly inaccurate.

Even under lenient assumptions of below-average dispersion, and uniform sampling across the observed sampling range, less than $10 \%$ of non-significant trends within this data set would have been classified by statistical methods that had the necessary power to detect isotopic shifts of $\leq 1 \%$ in $\delta^{15} \mathrm{~N}$ throughout life. This suggests that no conclusion may be safely drawn from the majority of non-significant body size $\delta^{15} \mathrm{~N}$ trends. The present study provides several recommendations for improvement. First, improvements in power can be achieved by sampling wider size ranges. Where there is an inability to do so, additional sampling effort will be needed. However, be careful when trying to expand $\Delta L_{\max }$ and make sure regression diagnostics are checked to see whether any higher length or weights, relative to the rest of the data set, are influencing the regression coefficients. Second, the explicit consideration and, where possible, reduction of variance is worthwhile for robust analysis. Finally, when describing non-significant size-based feeding of fishes the correlation coefficient should be defined and the power of the test should be assessed in order to detect ecologically meaningful shifts.

Acknowledgements. Funding was provided by a postdoctoral fellowship from Concejo Nacional de Investigación Científica y Técnica (CONICET) and CONICET/R09/639 (DEG), NERC grant NE/D013437/1 (CJS), and a NERC studentship NE/ F010664/1 (WDKR).

\section{LITERATURE CITED}

Barnes C, Jennings S (2007) Effect of temperature, ration, body size and age on sulphur isotope fractionation in fish. Rapid Commun Mass Spectrom 21:1461-1467

Barnes C, Jennings S, Barry JT (2009) Environmental correlates of large-scale spatial variation in the $\delta^{13} \mathrm{C}$ of marine animals. Estuar Coast Shelf Sci 81:368-374

Bearhop S, Adams CE, Waldron S, Fuller RA, Macleod H (2004) Determining trophic niche width: a novel approach using stable isotope analysis. J Anim Ecol 73:1007-1012

Bunn SE, Loneragan NR, Kempster MA (1995) Effects of acid washing on stable-isotope ratios of $\mathrm{C}$ and $\mathrm{N}$ in penaeid shrimp and seagrass-Implications for food-web studies using multiple stable isotopes. Limnol Oceanogr 40: $622-625$

Cocheret de la Moriniére E, Pollux B, Nagelkerken I, Hemminga M, Huiskes A, van der Velde G (2003) Ontogenetic dietary changes of coral reef fishes in the mangroveseagrass-reef continuum: stable isotopes and gut-content analysis. Mar Ecol Prog Ser 246:279-289

Cohen JE, Pimm SL, Yodzis P, Saldana J (1993) Body sizes of animal predators and animal prey in food webs. J Anim Ecol 62:67-78 
Cottingham KL, Lennon JT, Brown BL (2005) Knowing when to draw the line: designing more informative ecological experiments. Front Ecol Environ 3:145-152

Davenport SR, Bax NJ (2002) A trophic study of a marine ecosystem off southeastern Australia using stable isotopes of carbon and nitrogen. Can J Fish Aquat Sci 59:514-530

> Dupont WD, Plummer WD (1998) Power and sample size calculations for studies involving linear regression. Control Clin Trials 19:589-601

Froese R, Pauly D (eds) (2009) FishBase. World Wide Web electronic publication. www.fishbase.org version (07/2009) (accessed 07/2009)

Graham BS, Grubbs D, Holland K, Popp BN (2007) A rapid ontogenetic shift in the diet of juvenile yellowfin tuna from Hawaii. Mar Biol 150:647-658

> Hesslein RH, Hallard KA, Ramlal P (1993) Replacement of sulfur, carbon, and nitrogen in tissue of growing broad whitefish (Coregonus nasus) in response to a change in diet traced by $\delta^{34} \mathrm{~S}, \delta^{13} \mathrm{C}$ and $\delta^{15} \mathrm{~N}$. Can J Fish Aquat Sci 50:2071-2076

Jennings S, Warr KJ (2003) Environmental correlates of largescale spatial variation in the $\delta^{15} \mathrm{~N}$ of marine animals. Mar Biol 142:1131-1140

> Jennings S, Greenstreet SPR, Hill L, Piet GJ, Pinnegar JK, Warr KJ (2002) Long-term trends in the trophic structure of the North Sea fish community: evidence from stableisotope analysis, size-spectra and community metrics. Mar Biol 141:1085-1097

> Jennings S, Barnes C, Sweeting CJ, Polunin NVC (2008a) Application of nitrogen stable isotope analysis in sizebased marine food web and macroecological research. Rapid Commun Mass Spectrom 22:1673-1680

Jennings S, Maxwell TAD, Schratzberger M, Milligan SP (2008b) Body-size dependent temporal variations in nitrogen stable isotope ratios in food webs. Mar Ecol Prog Ser 370:199-206

Layman CA, Winemiller KO, Arrington DA, Jepsen DB (2005) Body size and trophic position in a diverse tropical food web. Ecology 86:2530-2535

Layman CA, Quattrochi JP, Peyer CM, Allegeier JE (2007) Niche width collapse in a resilient top predator following ecosystem fragmentation. Ecol Lett 10:937-944

Menard F, Lorrain A, Potier M, Marsac F (2007) Isotopic evidence of distinct feeding ecologies and movement patterns in two migratory predators (yellowfin tuna and swordfish) of the western Indian Ocean. Mar Biol 153: $141-152$

Mill AC, Sweeting CJ, Barnes C, Al-Habsi SH, MacNeil MA (2008) Mass-spectrometer bias in stable isotope ecology. Limnol Oceanogr Methods 6:33-39

Murry BA, Farrell JM, Teece MA, Smyntek PM (2006) Effect of lipid extraction on the interpretation of fish community

Editorial responsibility: Ivan Nagelkerken,

Nijmegen, Netherlands trophic relationships determined by stable carbon and nitrogen isotopes. Can J Fish Aquat Sci 63:2167-2172

Nagelkerken I, van der Velde G (2004) Relative importance of interlinked mangroves and seagrass beds as feeding habitats for juvenile reef fish on a Caribbean island. Mar Ecol Prog Ser 274:153-159

Pértega Díaz S, Pita Fernández S (2002) Determinación del tamaño muestral para calcular la significación del coeficiente de correlación lineal. In: Cadena de Atención Primaria, Vol 9. Complejo Hospitalario-Universitario Juan Canalejo, A Coruña, p 209-211

Peters RH (1983) The ecological implications of body size. Cambridge University Press, Cambridge

Post DM, Layman CA, Arrington DA, Takimoto G, Quattrochi J, Montana CG (2007) Getting to the fat of the matter: models, methods and assumptions for dealing with lipids in stable isotope analyses. Oecologia 152:179-189

R Development Core Team (2007) R: a language and environment for statistical computing. R Foundation for Statistical Computing, Vienna, Austria

Rau GH, Sweeney RE, Kaplan IR, Mearns AJ, Young DR (1981) Differences in animal ${ }^{13} \mathrm{C},{ }^{15} \mathrm{~N}$ and D abundance between a polluted and an unpolluted coastal site-likely indicators of sewage uptake by a marine food web. Estuar Coast Shelf Sci 13:701-707

Reid WDK, Clarke S, Collins MA, Belchier M (2007) Distribution and ecology of Chaenocephalus aceratus (Channichthyidae) around south Georgia and Shag Rocks (Southern Ocean). Polar Biol 30:1523-1533

Ryther J (1969) Photosynthesis and fish production in the sea. Science 166:72-76

> Stergiou KI, Karpouzi VS (2001) Feeding habits and trophic levels of Mediterranean fish. Rev Fish Biol Fish 11: 217-254

> Sweeting CJ, Jennings S, Polunin NVC (2005) Variance in isotopic signatures as a descriptor of tissue turnover and degree of omnivory. Funct Ecol 19:777-784

Sweeting CJ, Polunin NVC, Jennings S (2006) Effects of chemical lipid extraction and arithmetic lipid correction on stable isotope ratios of fish tissues. Rapid Commun Mass Spectrom 20:595-601

Sweeting CJ, Barry J, Barnes C, Polunin NVC, Jennings S (2007a) Effects of body size and environment on diettissue $\delta^{15} \mathrm{~N}$ fractionation in fishes. J Exp Mar Biol Ecol 340:1-10

> Sweeting CJ, Barry J, Polunin NVC, Jennings S (2007b) Effects of body size and environment on diet-tissue $\delta^{13} \mathrm{C}$ fractionation in fishes. J Exp Mar Biol Ecol 352:165-176

Wells RJD, Cowan JH, Fry B (2008) Feeding ecology of red snapper Lutjanus campechanus in the northern Gulf of Mexico. Mar Ecol Prog Ser 361:213-225

Zuur AF, Ieno EN, Smith GM (2007) Analysing ecological data. Springer Science + Business Media, New York

Submitted: October 5, 2009; Accepted: February 4, 2010

Proofs received from author(s): April 27, 2010 